\title{
A Novel One-Pot Conversion of Tetraacetal Tetraoxa-Cages to Aza-Cages Mediated by Iodotrimethylsilane in Acetonitrile
}

\author{
Hsien-Jen Wu* and Jyh-Haur Chern \\ Department of Applied Chemistry, National Chiao Tung University, Hsinchu, Taiwan, China
}

\begin{abstract}
Treatment of the tetraacetal tetraoxa-cages 1a-f with excess of iodotrimethylsilane in acetonitrile at $25{ }^{\circ} \mathrm{C}$ gave the novel tetraacetal trioxamonoaza-cages $2 \mathbf{a}-\mathbf{f}$ in $75-80 \%$ yields respectively, a novel one-pot conversion of oxa-cages to aza-cages. (๑) 1997 Elsevier Science Ltd.
\end{abstract}

The reaction chemistry of acetals has been greatly expanded by the use of Lewis acidic promoters particularly in conjunction with silicon-containing nucleophlies. ${ }^{1,2}$ Usually, acyclic and monocyclic acetals, especially the acetal groups in monosaccharide derivatives, are the objects for study. ${ }^{3}$ Recently, we accomplished the synthesis of novel oxa-cage compounds, such as tetraacetal tetraoxa-cages, ${ }^{4}$ tetraacetal pentaoxa-cages, ${ }^{5}$ triacetal trioxa-cages, ${ }^{6}$ diacetal trioxa-cages, ${ }^{7}$ and pentaacetal pentaoxa-cages (the pentaoxa[5]-peristylanes) ${ }^{8}$ All these oxacages have acetal and ketal groups on the molecule. As part of a program that involves the synthesis, chemistry, and applications of new heterocyclic cages, we report here a novel one-step conversion of oxa-cages to aza-cages mediated by $\mathrm{Me}_{3} \mathrm{SiI}$, leading to formation of novel tetraacetal trioxamonoaza-cages. To our knowledge, a one-pot conversion of acetal group to monoazaacetal group mediated by $\mathrm{Me}_{3} \mathrm{SiI}$ has not yet been reported., ${ }^{1,2}$

Reaction of the tetraacetal tetraoxa-cages 1a-1f with three equivalents or more of iodotrimethylsilane in acetonitrile at $25{ }^{\circ} \mathrm{C}$ for $4 \mathrm{~h}$ gave the novel aza-cages $2 \mathrm{a}-2 \mathrm{f}$ in $80-85 \%$ yields (Scheme 1). This novel conversion takes place regioselectively on the $\mathrm{C}(3)-\mathrm{O}(4)$ or $\mathrm{O}(4)$ $\mathrm{C}(5)$ bond. No detectable amount of the other regioisomers 3,4 , or 5 was obtained. We attribute the highly regioselective oxygen-nitrogen conversion reaction to the unusually large bond angle 
of $\mathrm{C}(3)-\mathrm{O}(4)-\mathrm{C}(5)$ of the tetraoxa-cages 1 . While the other C-O-C bond angles of these tetraoxacages are in between $111^{\circ}-108^{\circ}$, the $\mathrm{C}(3)-\mathrm{O}(4)-\mathrm{C}(5)$ bond angle is $117.5^{\circ}$, remarkably larger than the ordinary bond angles with sp $^{3}$-hybridized atoms. ${ }^{4 a}$ The stability and size of the ring may also be an important factor for the high regioselectivity. In the case of $1 \mathrm{a}$, only $2 \mathrm{a}$ was obtained. Thus, the steric factor for the regioselective conversion was excluded. Reaction of 1 with excess of chlorotrimethylsilane in acetonitrile at $25{ }^{\circ} \mathrm{C}$ remained unchanged. The structure of the azacages 2a-2f was finally proven by X-ray analysis of the crystalline compound $2 \mathbf{d}$ (Figure 1). The conformation of the nitrogen atom with respect to the apical carbon atom was shown to be in a boat form. The bond angle of $\mathrm{C}(3)-\mathrm{N}(4)-\mathrm{C}(5)$ is $119.5^{\circ}$.

\section{Scheme 1}

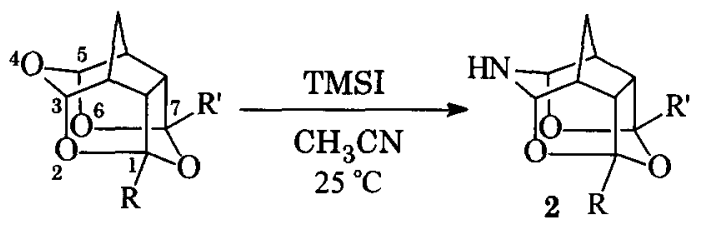
1 a $\mathrm{R}=\mathrm{R}^{\prime}=\mathrm{H}$
b $\mathrm{R}=\mathrm{H}, \mathrm{R}=\mathrm{CH}_{3}$
c $\mathrm{R}=\mathrm{H}, \mathrm{R}^{\prime}=\mathrm{CH}_{2} \mathrm{Ph}$
d $\mathrm{R}=\mathrm{R}^{\prime}=\mathrm{CH}_{3}$
e $\mathrm{R}=\mathrm{CH}_{3}, \mathrm{R}^{\prime}=\mathrm{CH}_{2} \mathrm{Ph}$
f $\mathrm{R}=\mathrm{R}^{\prime}=\mathrm{Ph}$

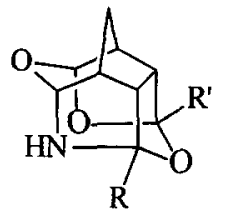

3

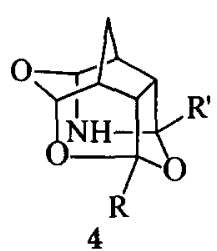

4

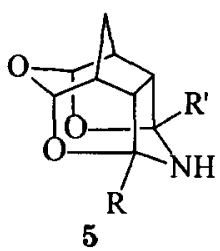

5

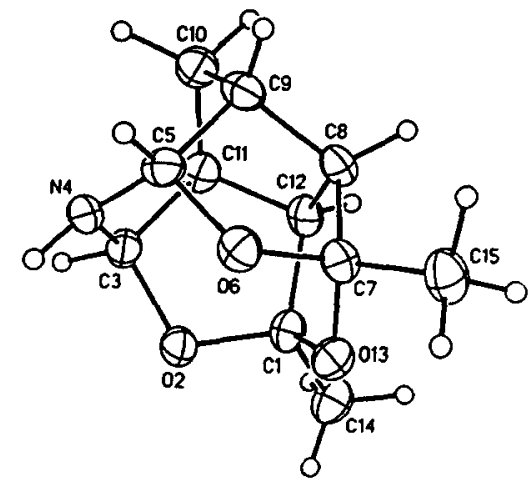

Figure 1. ORTEP diagram of $\mathbf{2 d}$

Reaction of 1a, 1d, and $1 \mathrm{f}$ with one equivalent of $\mathrm{Me}_{3} \mathrm{SiI}$ in acetonitrile at $0{ }^{\circ} \mathrm{C}$ for $2 \mathrm{~h}$ gave the ring expansion products $6 \mathbf{a}-6 \mathrm{c}$ in $85-90 \%$ yields (Scheme 2). Treatment of $6 \mathrm{a}-6 \mathrm{c}$ with excess of $\mathrm{Mes}$ SiI in acetonitrile at $25^{\circ} \mathrm{C}$ gave the aza-cages $2 \mathrm{a}, \mathbf{2 d}$, and $2 \mathrm{f}$ in $80 \%$ yields. Thus, the ring 
expansion compound 6 is the intermediate of the conversion of oxa-cage 1 to aza-cage 2 . The proposed mechanism for this interesting reaction involves a Ritter-type reaction ${ }^{9}$ of the oxonium ion 7 with acetonitrile via the nitrilium ion 8 to give the intermediate 6 .

\section{Scheme 2}

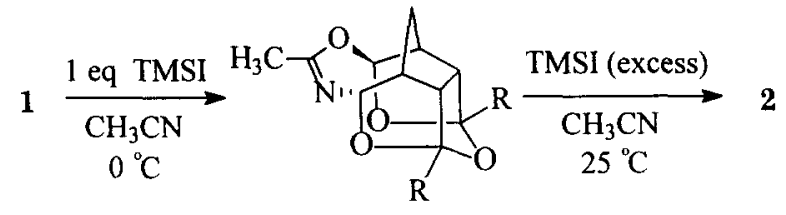

$$
\begin{aligned}
6 \text { a } \mathrm{R} & =\mathrm{H} \\
\text { b } \mathrm{R} & =\mathrm{CH}_{3} \\
\text { c } \mathrm{R} & =\mathrm{Ph}
\end{aligned}
$$

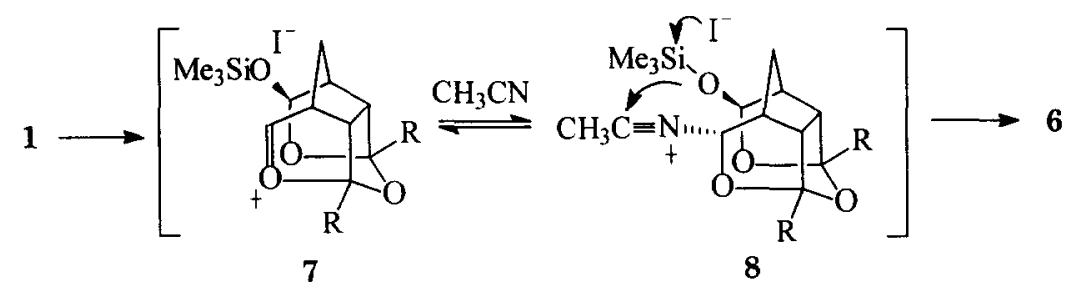

Reaction of $1 \mathrm{a}, 1 \mathrm{~d}$, and $1 \mathrm{f}$ with Lewis acids, such as $\mathrm{TiCl}_{4}$ and $\mathrm{BF}_{3} \cdot \mathrm{OEt}_{2}$, in acetonitrile at 25 ${ }^{\circ} \mathrm{C}$ for $4 \mathrm{~h}$ gave the hydride rearrangement products $9 \mathrm{a}-9 \mathrm{c}$ in $80 \%$ yields (Scheme 2). No detectable amount of the corresponding aza-cages $2 \mathrm{a}, \mathbf{2 d}$, and $2 \mathrm{f}$ was obtained. We attribute the highly regioselective hydride rearrangement to the unusually large bond angle of $\mathrm{C}(3)-\mathrm{O}(4)$ - $\mathrm{C}(5)$ of the tetraoxa-cages 1 . In the case of $1 \mathbf{a}$, only $9 \mathrm{a}$ was obtained.

\section{Scheme 3}

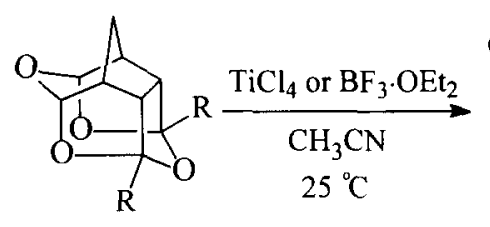

1a, 1d, $1 \mathrm{f}$

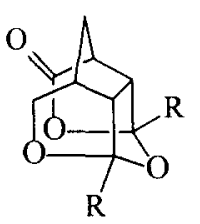

9 a $\mathrm{R}=\mathrm{H}$

b $\mathrm{R}=\mathrm{CH}_{3}$

c $\mathrm{R}=\mathrm{Ph}$

Acknowledgment: We thank the National Science Council of the Republic of China for financial support (Grant No. NSC85-2113-M009-004). We also thank Dr. S. L. Wang and Miss F. L. Liao (at the Department of Chemistry, National Tsing Hua University) for their help in carrying out $\mathrm{X}$-ray crystallographic analysis. 


\section{References}

1. For reviews: (a) Mukaiyama, T.; Murakami, M. Synthesis 1987, 1043. (b) Hosomi, A.; Endo, M.; Sakurai, H. Chem. Lett. 1976, 941.

2. (a) Mukaiyama, T.; Hayashi, M. Chem. Lett. 1974, 15. (b) Hosomi, A.; Sakurai, H. Tetrahedron Lett. 1976, 1295. (c) Kende, A. S.; Johnson, S.; Sanfilippo, P.; Hodges, J. C.; Jungheim, L. N. J. Am. Chem. Soc. 1986, 108, 3513. (d) Mori, I.; Ishihara, K.; Flippin, L. A.; Nozaki, K.; Yamamoto, H.; Bartlett, P. A.; Heathcock, C. H. J. Org. Chem. 1990, 55, 6107. (e) Mori, A.; Ishihara, K.; Yamamoto, H. Tetrahedron Lett. 1986, 27, 987. (f) Denmark, S. E.; Almstead, N. G. J. Am. Chem. Soc. 1991, 113, 8089. (g) Denmark, S. E.; Almstead, N. G. J. Org. Chem. 1991, 56, 6458.

3. (a) Ratcliffe, A. J.; Konradsson, P.; Fraser-Reid, B. J. Am.Chem. Soc. 1990, 112, 5665 . (b) Pavia, A. A.; Ung-Chhun, S. N.; Durand, J. L. J. Org. Chem. 1981, 46, 3158. (c) Gordon, D. M.; Danishefsky, S. J. Org. Chem. 1991, 56, 3713. (d) Sano, H.; Mio, S.; Tsukaguchi, N.; Sugai, S. Tetrahedron 1995, 51, 1387. (e) Noort, D.; van der Marel, G. A.; Mulder, G. J.; van Boom, J. H. Synlett 1992, 224.

4. (a) Wu, H. J.; Lin, C. C. J. Org. Chem. 1995, 60, 7558. (b0 Wu, H. J.; Lin, C. C. J. Org. Chem. 1996, 61, 3820. (c) Wu, H. J.; Huang, F. J.; Lin, C. C. J. Chem. Soc., Chem. Commun. 1991, 770. (d) Lin, C. C.; Wu, H. J. J. Chin. Chem. Soc. 1995, 42, 815. (e) Lin, C. C.; Huang, F. J.; Lin, J. C.; Wu, H. J. J. Chin. Chem. Soc. 1996, 43, 177. (f) Lin, R. L.; Wu, C. Y.; Chern, J. H.; Wu, H. J. J. Chin. Chem. Soc. 1996, 43, 289. (g) Wu, H. J.; Chern, J. H.; Wu, C. Y. Submitted for publication.

5. Lin, C. C.; Wu, H. J. Synthesis 1996, 715.

6. Wu, C. Y.; Lin, C. C.; Lai, M. C.; Wu, H. J. J. Chin. Chem. Soc. 1996, 43, 187.

7. (a) Wu, H. J.; Tsai, S. H.; Chung, W. S. J. Chem. Soc., Chem. Commun. 1996, 375. (b) Wu, H. J.; Tsai, S. H.; Chung, W. S. Tetrahedron Lett. (in press)

8. Wu, H. J.; Wu, C. Y. submitted for publication.

9. (a) Senanayake, C. H.; Roberts, F. E.; DiMichele, L. M.; Ryan, K. M.; Liu, J.; Fredenburgh, L. E.; Foster, B. S.; Douglas, A. W.; Larsen, R. D.; Verhoeven, T. R.; Reider, P. J.; Tetrahedron Lett. 1995, 36, 3993. (b) Ritter, J. J.; Minieri, P. P. J. Am. Chem. Soc. 1948, 70, 4045. (c) Bishop, R. Comprehensive Org. Syn. 1991, 6, 261. 